\title{
NUMERICAL INVESTIGATIONS OF TOOL LIFE IN THIXOFORGING IN CONSIDERATION OF THE WORKPIECE IN THE SEMI-SOLID STATE
}

\author{
Bernd-Arno BEHRENS, Alexander CHUGREEV, Maiwand HOOTAK \\ Leibniz Universität Hannover, Institute of Forming Technology and Machines, Garbsen, Germany, EU, \\ hootak@ifum.uni-hannover.de
}

https://doi.org/10.37904/metal.2019.696

\begin{abstract}
The present contribution deals with numerical investigations of a challenging forming process called thixoforming. This technology takes advantage of the semi-solid material state in order to produce geometrically complex parts. The reliability of numerical investigations of such processes depends on the accuracy of the used input data. Current commercial FEA software packages provide material databases with a great amount of material properties for diverse materials. However, material properties valid for temperature ranges exceeding the solidus temperatures are often insufficiently described or at times not available at all. Since thixoforming of steel requires the aforesaid temperature ranges a material model, consisting of two sections, has been developed for the numerical description of thixoforming processes. The first one describes the material behaviour below the solidus temperature and comprises an approach from structure mechanics, whereas the second section model describes the thixotropic behaviour above the solidus temperature based on the Ostwald-de Waele power law. An appropriate material description enables the investigation of the life cycle of tools by calculating local thermal and mechanical stresses more accurately. In this context numerical calculations of the thermo-mechanical tool loads during thixoforging were carried out. The Sehitoglu's fatigue model has been implemented in the commercial FE software Simufact.forming by means of user-defined subroutines. In addition low-cycle fatigue as well as thermo-mechanical fatigue tests were performed in order to calibrate the model.
\end{abstract}

Keywords: Tool life, fatigue model, thixoforming, FEA, process simulation

\section{INTRODUCTION}

The failure of dies in thixoforming is essentially caused due to three types of damage (corrosive, tribological and mechanical) [1,2]. So far, long-term tool behaviour in thixoforming has only been examined numerically in isolated cases. The basis for this is the realistic mapping of the flow behaviour of semi-solid metals in order to reproduce the loads on the tool more accurately. The reliability of numerical investigations depends on the accuracy of the used input data [3]. A precise set of input data is necessary for a realistic development of any material model. Current commercial FEA software packages provide material databases with a great amount of material properties for diverse materials. However, material properties valid for temperature ranges which exceed the solidus temperatures are often insufficiently described or at times not described at all. Therefore, this paper presents the development of an appropriate mathematical model describing the plastic flow behaviour of $100 \mathrm{Cr} 6$ in the thixotropic state and its implementation in a commercial FE software. The goal is to receive a more accurate model capable of determining more realistic results in simulations of thixoforming processes by considering thixotropic material behaviour. This will allow determining the thermal and mechanical stresses more accurately which is the basis for the service life calculation [4].

\section{MODELLING THE MATERIAL BEHAVIOUR}

During a thixoforming process, the material adopts both a solid and thixotropic state, as different areas of the workpiece reach different temperatures. Thus, areas below the solidus temperature $T_{S}$ require a structuremechanical description (e. g. Hensel-Spittel), whereas the areas exceeding solidus temperature are described 
by fluid-mechanical models (e. g. Ostwald-de Waele approach). This relationship can be expressed mathematically by a sectionwise defined function, as shown below:

$f(\varphi, \dot{\varphi}, T), T<T_{s}$

$f(\eta, T), \quad T>T_{S}$

These functions describe the flow behaviour of the flow curves. Hence, below the solidus temperature the flow curve $k_{f}$ is described by a function depending on the temperature $T$, the degree of deformation $\varphi$ and the strain rate $\dot{\varphi}$. Above the solidus temperature, a fluid mechanical approach is applied. The relationship between flow stress and viscosity $\eta$ is described by the following equation [5]:

$\mathrm{f}(\eta, \mathrm{T}) \Leftrightarrow \mathrm{k}_{\mathrm{f}}=3 \cdot \eta \cdot \dot{\varepsilon}_{\mathrm{v}}$

where $\dot{\varepsilon}_{v}$ is the equivalent strain rate. The viscosity is described by the Ostwald-de-Waele power law:

$\eta=K(T) \cdot \dot{\gamma}^{\mathrm{n}(\mathrm{T})-1}$

where $K$ and $n$ are the consistency of the material and the shear exponent, respectively, which are dependent on the temperature. These parameters have been deduced from viscosity values taken from literature [6]. For this reason, an exponential and a linear approach have been chosen for the description of $K(T)$ and $n(T)$, respectively. Therefore, the section wise defined function can be written as:

$k_{f}=\left\{\begin{array}{rr}f(\varphi, \dot{\varphi}, T), & T<T_{S} \\ 3 \cdot K(T) \cdot \dot{\gamma}^{n(T)-1} \cdot \dot{\varepsilon}_{v}, & T>T_{S}\end{array}\right.$

where $K(T)=A \cdot e^{B \cdot T}$ and $n(T)=C \cdot T+D$ are the trial functions.

To determine these parameters, shear rate and temperature-dependent viscosity curves have been used [5]. The material model was implemented in a commercial FE software Simufact.forming by means of user-defined subroutines. The validation of the sectionwise defined model was carried out using a quenching and deformation dilatometer DIL $805 \mathrm{~A} / \mathrm{D}+\mathrm{T}$ (Figure 1) which can be applied for tensile, compression and quenching tests. Numerical and experimental investigations of special upsetting tests were designed and carried out. Finally, the model parameters were fitted by reverse engineering (for detailed procedure see [5]).

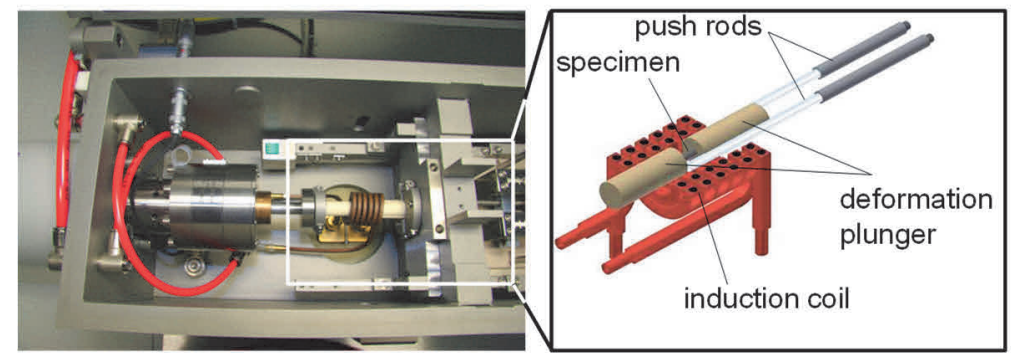

Figure 1 Deformation dilatometer in compression mode

\section{DAMAGE DUE TO THERMO-MECHANICAL FATIGUE}

The term damage in the context of thermo-mechanical fatigue describes all processes that can shorten component service life or impair its function. Depending on the extended temperature range, fatigue, creep 
and corrosion damage can be considered. The thermo-mechanical fatigue (TMF) life prediction model developed by Sehitoglu et al. [6] is based on the accumulation of these partial damages:

$D^{\text {tot }}=D^{f a t}+D^{o x}+D^{\text {creep }} \Leftrightarrow \frac{1}{N^{\text {tot }}}=\frac{1}{N^{\text {fat }}}+\frac{1}{N^{o x}}+\frac{1}{N^{\text {creep }}}$

$D^{f a t}$ results from a superposition of the Coffin-Manson and Basquin relationship. In $D^{o x}$, the thickness of the oxide layer, which is described by a diffusion approach, and total strain amplitude are included. $D^{\text {creep }}$ is modelled with a Norton approach [7]. $D^{o x}$ and $D^{\text {creep }}$ each contain factors that determine the dependency of the damage mechanisms from the phase position. $D^{\text {tot }}$ is the sum of the three damage proportions. Their reciprocals are the corresponding numbers of cycles until failure. Due to the various micro mechanisms affecting the behaviour of materials under isothermal and thermo-mechanical loading conditions, a profound understanding is required. For this purpose, Sehitoglu et al. developed their model to take into account all damage mechanisms operating under variable strain-temperature conditions which are not covered by individual isothermal tests alone. Therefore Sehitoglu's life prediction model allows for the calculation of crack formation and early crack growth due to fatigue, environmental and creep damage. This method includes several material parameters that can be determined by special isothermal and thermo-mechanical tests.

\section{NUMERICAL ESTIMATION OF THERMO-MECHANICAL TOOL LOADS}

Within the scope of the present work, simulations using the finite element method (FEM) for thixoforming were carried out. By means of the simulation results, the thermo-mechanical loads of the tools in single and continuous operation were determined in order to evaluate the thixoforging process effects. The evaluation was carried out holistically taking into account stress conditions, temperature fields and deformations of the tools. These investigations made statements about stationary stress and temperature developments in the tool material possible. For this purpose, FE simulations (Figure 2) were carried out using Simufact.forming, in which every step of the real process, including the transport of raw parts from the heating equipment to the forming equipment, was simulated. The visco-plastic material properties and thus the thermo-mechanical loads of the tools were taken into account. First, the loads of a single forming process were analyzed. The continuous operation was then simulated in order to investigate how temperatures, stresses and deformations in the tools develop under cyclic loading.
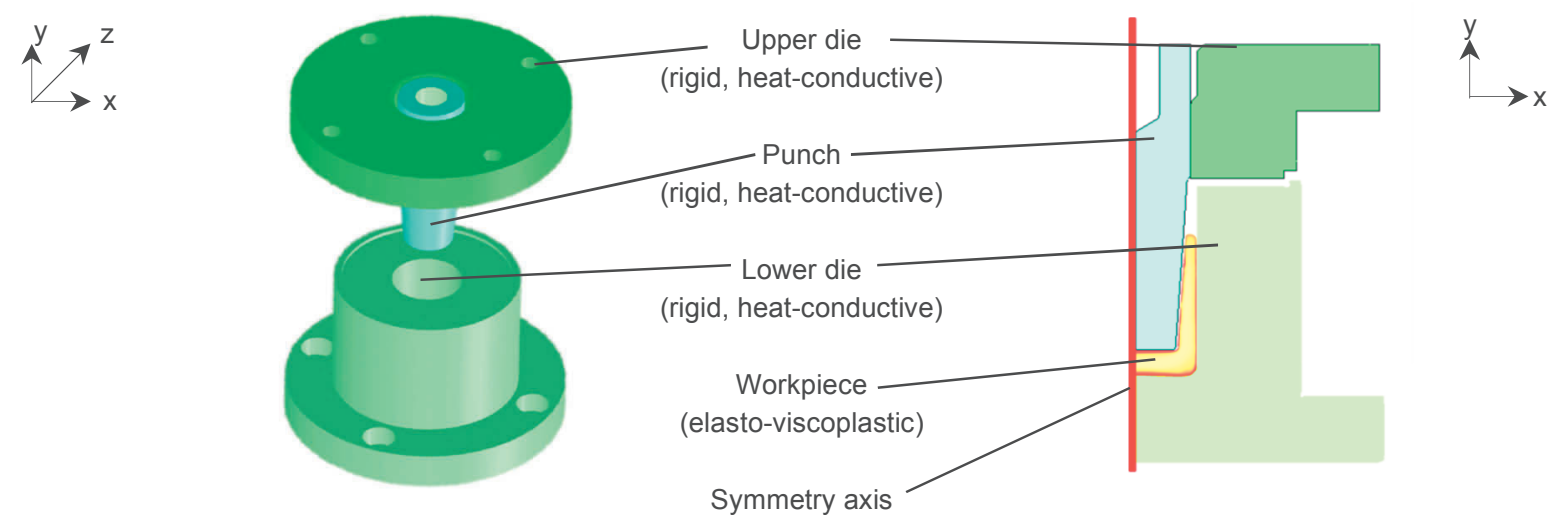

(a)

(b)

Figure 2 FE setup 3D-geometry (a), 2D-geometry (b)

The investigations revealed that after few cycles plastic deformation of the tools was observed due to raised temperatures (cf. Figure 3a, blue curve). For this reason, the time intervals of the sub-processes were adapted in the course of process adjustment, while the total duration of a forming cycle remained the same. The process 
steps in which the upper tool is subjected to strong heating were shortened, whereas the steps in which the upper tool cools down extended. In addition, the transport time of the billet from the heating system to the lower die was shortened (from $5 \mathrm{~s}$ to $3 \mathrm{~s}$ ), resulting in a lower temperature gradient in the workpiece at the start of forming. In addition, the outcome was a higher liquid phase fraction in the edge area of the billet, so that lower forming forces were required. This was additionally supported by a reduction in residence time (from $5 \mathrm{~s}$ to $1 \mathrm{~s}$ ) of the billet on the lower die before forming in subsequent simulations. By reducing post-compaction time (from $7 \mathrm{~s}$ to $1 \mathrm{~s}$ ), the heat exchange with the tool was reduced, so that less heating of the tools was expected. The following Figure 3 illustrates that within the adjusted process, even in the tenth cycle, lower temperatures were present in the mandrel radius (marked by blue circle in Figure $3 \mathbf{b}$ of the punch before the start of forming than in the fourth cycle of the specified process sequence. This is decisive for mechanical stability. It is also evident that the maximum temperature in the process cycle approaches a stationary value of $1300{ }^{\circ} \mathrm{C}$ after ten cycles. The minimum temperature approaches a value of approx. $1000{ }^{\circ} \mathrm{C}$. This means the upper tool experiences a temperature fluctuation at the surface of approx. $300{ }^{\circ} \mathrm{C}$ per cycle within continuous operation.

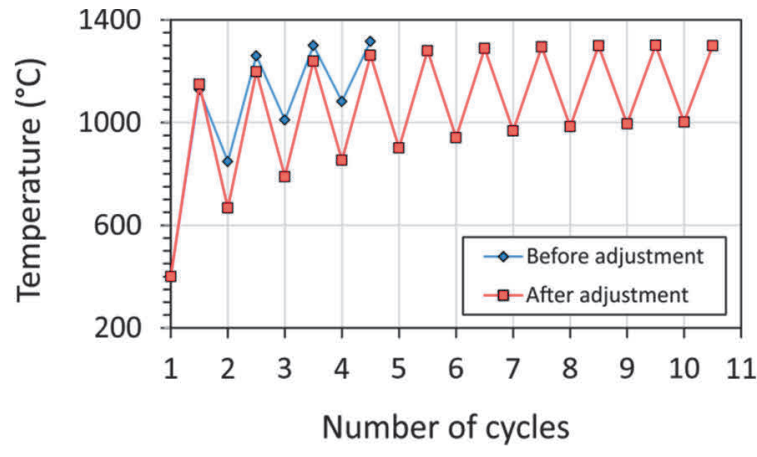

(a)

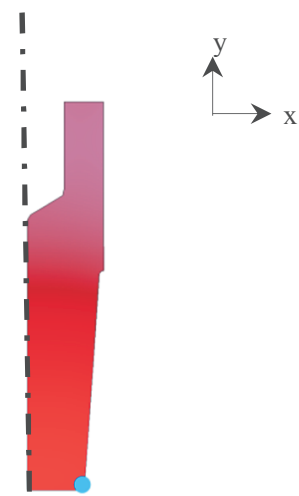

(b)

Figure 3 Punch temperature development on mandrel radius before and after adjustment (a), punch with marked (blue dot) mandrel radius (b)

\section{LOW-CYCLE FATIGUE AND THERMO-MECHANICAL EXPERIMENTS}

To calculate the parameters of the Sehitoglu's model, following experiments have been performed. As described above, the Sehitoglu approach can be used to determine the total damage consisting of mechanical damage $D^{f a t}$, creep damage $D^{\text {creep }}$ and environmental damage $D^{o x}$. The low-cycle fatigue (LCF) tests were carried out on the material testing system Gleeble 3800-GTC at the IFUM to parameterise the mechanical part according to Manson-Coffin-Basquin. The specimens (material 1.2367) were heated conductively and cyclically loaded with the constant strain amplitude isothermally in air $\left(20^{\circ} \mathrm{C}\right.$ and $600{ }^{\circ} \mathrm{C}$, respectively; strain ratio $R=-1$ ). In addition, so-called out-of-phase thermo-mechanical fatigue (TMF) tests on a TMF testing machine (LFV 25-HH-S)were performed, where the amplitude of temperature $\left(300^{\circ} \mathrm{C}-750^{\circ} \mathrm{C}\right.$ ) and strain are not in phase and has a shift of $180^{\circ}$. Notification of crack initiation is possible by the stress amplitude and its sudden drop. LCF studies mentioned in literature show that the room temperature strain-life curve can be considered an upper bound on life. In [8] the lives of all test specimens were found to be less than or approximately equal to those during room temperature tests. Any decrease in life can be attributed to oxidation effects, creep effects, or both $[9,10]$. For this purpose the isothermal test was also performed at $600{ }^{\circ} \mathrm{C}$ to verify and confirm the experiences from conducted studies.

The number of cycles to crack initiation increases with decreasing strain amplitude (Figure 4). The influence of the significantly higher temperature on the earlier crack initiation is shown by the performance of the tests 
at $600{ }^{\circ} \mathrm{C}$. The contribution of oxidation and creep add up to the mechanical damage and thus cause an earlier failure of the material. These mechanisms are illustrated by performing the TMF tests, as isothermal tests alone do not capture all damage mechanisms that operate under variable strain-temperature conditions [10]. The results (Figure 4c) show much earlier specimen failure due to the combination of mechanical and thermal loads. This confirms experimental.

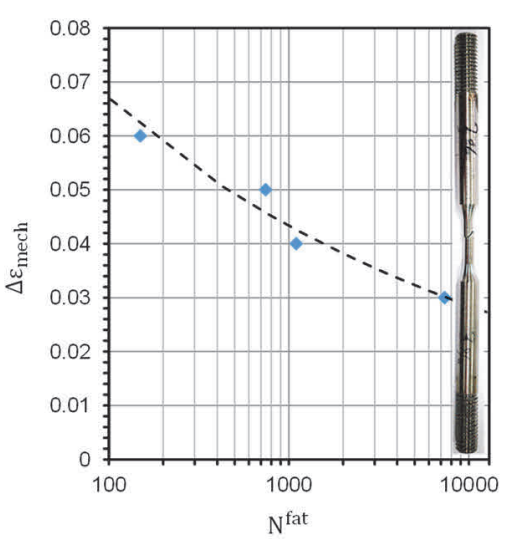

(a)

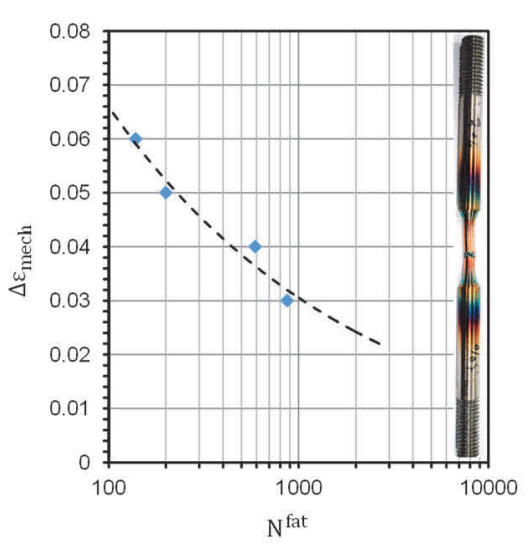

(b)

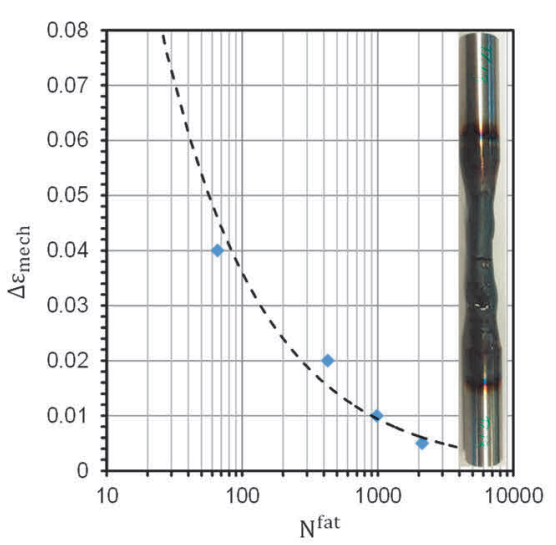

(c)

Figure 4 Experimental LCF and TMF results: specimen temperature $20^{\circ} \mathrm{C}(\mathrm{a}), 600^{\circ} \mathrm{C}(\mathrm{b}), 300-750{ }^{\circ} \mathrm{C}(\mathrm{c})$

\section{IMPLEMENTATION OF SEHITOGLU'S MODEL}

Figure 5 shows the results of the simulation model after implementing the Sehitoglu's Model. However for the LCF simulation only the mechanical fatigue part of the model has been applied for the calculation of the cycle until specimen failure for different strains. As a first approximation the coefficients were chosen from literature [6]. It is visible that the results can be approached by a power law relation fairly accurately but there is a discrepancy comparing the numerical with experimental results. For this reason the experimental results serve for the calibration of the mechanical fatigue part. In this context, further steps include optimising the coefficients by fitting them by means of a corresponding MATLAB script. Thus, it will be possible to approach the experimental results and calibrate the model for this specific tool material.

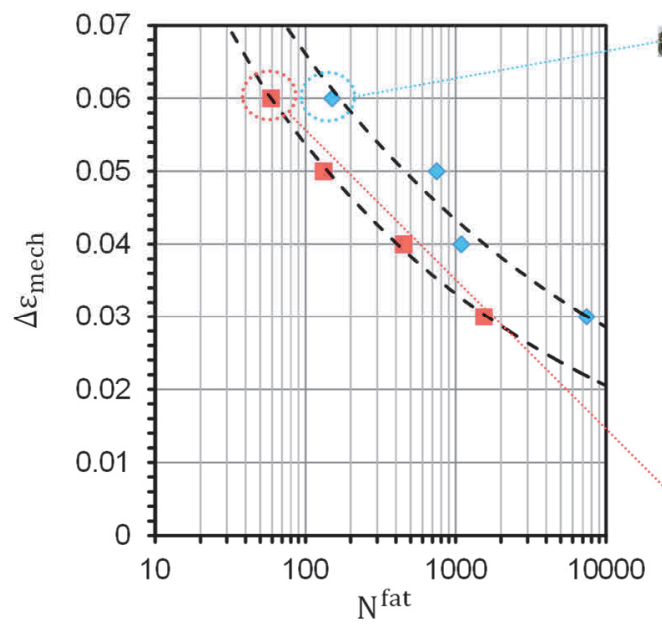

(a)

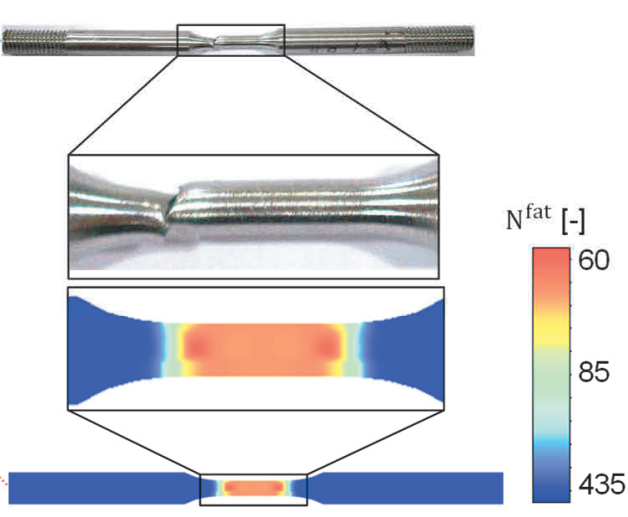

(b)

Figure 5 Comparison of experimental (blue) and numerical (red) LCF test results before calibration (a), specimen state from experiment and simulation for strain amplitude 0.06 (b) 


\section{CONCLUSION AND OUTLOOK}

In this work numerical investigations of tool life in thixoforging of steel parts have been presented. For this purpose at first the material has been modelled in consideration of the workpiece in the semi-solid state. The TMF life prediction model of Sehitoglu was used. Besides, the numerical design of a simple thixoforging process was presented and calculation of the thermo-mechanical tool loads was carried out. This data form the basis for upcoming fatigue tool life calculation. Results of the LCF and TMF experiments were shown. Comparing experimental and numerical LCF results revealed discrepancies. The accurate coefficients will be determined by fitting these by means of a MATLAB script. In addition, the model equations for the calculation of oxidation and creep damage components will be implemented in Simufact.forming using subroutines. After calibrating the entire model, based on the numerically determined thermo-mechanical tool loads, the proportions of the occurring damage components will be calculated.

\section{ACKNOWLEDGEMENTS}

The authors would like to thank the German Research Foundation (DFG) for financially supporting the research project "Numerical Calculation of Thermal Die Load and Die Life during Thixoforging of Steel" (project number 299534929) and Dr.-Ing. Mark Alan Swider from IW (Institut fuer Werkstoffkunde, LUH) for the kind support during the TMF tests.

\section{REFERENCES}

[1] MÜNSTERMANN, S. Tool Technologies for Forming of Semi-Solid Metals. Chapter In: Thixoforming: Semi-solid Metal Processing, pp.239-308.

[2] LUGSCHEIDER, E. HORNIG, T. PVD Hard Coatings Protecting the Surface of Thixoforming Tools. Advanced Engineering Materials. 2000. vol. 2, pp. 33-37.

[3] HIRT, G., SHIMAHARA, H., SEIDL, I., KUTHE, F., ABEL, D., SCHÖNBOHM, A. Semi-Solid Forging of 100Cr6 and X210CrW12 Steel. CIRP Annals. 2005. vol. 54, pp. 257-260.

[4] BEHRENS, B.-A., MATTHIAS, T. Finite Element Analysis of the Tool Load during Manufacturing of a Flange in a Semi-solid State. Conference: Proceedings from the 5th International Conference on Thermal Process Modeling and Computer Simulation, 2014.

[5] BEHRENS, B. A., CHUGREEV, A., HOOTAK, M. A sectionwise defined model for the material description of $100 \mathrm{Cr} 6$ in the thixotropic state. AIP Conference Proceedings 1960. 2018.

[6] SEHITOGLU, H., NEU, R. Thermomechanical Fatigue, Oxidation and Creep: Part I. Experiments. Metallurgical Transactions. 1989. vol. 20, pp. 1755-1767.

[7] HALÁSZI, Cs., NELHIEBEL, A., GAIER, C., DANNBAUER, H. Determination of the material parameters for Sehitoglu's TMF life prediction model. In: The 6th Engineering Integrity Society International Conference on Durability and Fatigue, At Cambridge. 2007.

[8] LOPEZ SANTAELLA, M. Thermo-mechanical fatigue of hot forging tools - prediction, analysis and optimization methods through six-sigma. in Umformtechnische Schriften. Band 169. 2014. p. 200.

[9] MOCELLIN, K., FERRARO, M., VELAY, V., LOGE, R., REZAI-ARIA, F. Numerical life prediction of mechanical fatigue for hot forging tools. International Journal of Materials Forming. 2009. vol. 2, pp.129-132.

[10] SAROOSH, M.A., LEE, H.-C., IM, Y.-T., CHOI, S.-W. High cycle fatigue life prediction of cold forging tools based on workpiece material property. Journal of Materials Processing Technology. 2007. vol. 191, pp. 178-181. 